\title{
Studi Sistem Tanam Jajar Legowo terhadap Peningkatan Produktivitas Padi Sawah
}

\author{
The studies of row planting system "Legowo" to the increased \\ productivity of lowland rice
}

\section{Misran}

\author{
Balai Pengkajian Teknologi Pertanian (BPTP) Sumatera Barat \\ Jl. Raya Padang-Solok Km 40 Sukarami, Telp. 0755-31564; Fax. 0755-31138
}

\begin{abstract}
The studies of row planting system "legowo" to the increased productivity of lowland rice. This research aims to determine the best planting system in order to obtain optimum growth and yield. The experiment site in lowland farmers Piruko Sitiung, Dharmasraya district, West Sumatra, from May to September 2009. The research using a randomized block design (RBD) with 4 replications and 5 treatments planting systems, namely: (A) the Row "Legowo" 2:1, (B) the Row "Legowo" 4:1, (C) the Row "Legowo" 6:1, (D) the Row "Legowo" 8:1, and (e) Without the Row "Legowo" Control. Fertilizers are used ; $200 \mathrm{~kg}$ Urea, $100 \mathrm{~kg}$ SP36, and $50 \mathrm{~kg} \mathrm{KCl} / \mathrm{ha}$. Urea and $\mathrm{KCl}$ are given three times with brocasting system at 1, 4, and 7 weeks after planting (wap), while the SP36 is given at 1 wap combined with Urea and $\mathrm{KCl}$. The seeds used Batang Piaman variety planted three seedling per hill, spacing of $25 \times 25 \mathrm{~cm}$. Data were collected on; plant height, maximum number of tillers/hill, number of productive tiller/hill, yield components, and yield. The results showed that "legowo" row planting system significantly affect the agronomic component plants, except at plant height. Against the yield components and the results also showed a marked influence on the percentage of empty grains unless and 1000 grain weight. "Legowo" row planting system can increase the yield of dry grain harvest around 19.90 to $22 \%$. This experiment suggests that in order to obtain optimum productivity of lawland rice is recommended to use of "Legowo" row planting system.
\end{abstract}

Keywords : "Legowo" row planting system, productivity, lawland rice.

Diterima : 03-03-2014, disetujui 02-05-2014

\section{PENDAHULUAN}

Rata-rata laju pertambahan penduduk Indonesia sekitar 1,27-1,29\% pertahun, dengan laju pertumbuhan tersebut pada tahun 2025 jumlah penduduk Indonesia diproyeksikan mencapai 296 juta jiwa dengan kebutuhan beras sekitar 41,5 juta ton atau setara dengan 78,3 juta ton gabah kering 

giling (Las et al., 2008). Dalam upaya memenuhi kebutuhan pangan utama masyarakat, pemerintah telah mencanangkan gerakan Peningkatan Produksi Beras Nasional (P2BN), hal ini bertujuan untuk meningkatkan produksi padi. Gerakan P2BN merupakan upaya yang terkoordinasi untuk memasyarakatkan teknologi dan inovasi baru melalui pendekatan pengelolaan tanaman dan sumberdaya terpadu (PTT) padi sawah. Lebih lanjut dinyatakan bahwa program P2BN menargetkan peningkatan produksi padi sebesar 2 juta ton pada tahun 2007 dan diharapkan ratarata meningkat sebesar 5\% per tahun pada tahun berikutnya (Purwanto, 2008).

Pembangunan pertanian tanaman pangan khususnya padi tetap terfokus kepada upaya peningkatan produksi yang harus diikuti dengan pengembangan usaha tani berbasis agribisnis agar dapat meningkatkan pendapatan petani. Menurut Nur et al. (2003), laju peningkatan produktivitas padi sawah di Indonesia cenderung melandai sehingga diindikasikan bahwa sistem intensifikasi padi sawah yang selama ini diterapkan belum mampu meningkatkan produksi dan produktivitas.

Sementara itu Hafsah (2003), menyatakan bahwa tantangan internal pembangunan tanaman pangan yang patut menjadi perhatian antara lain adalah: (1) Stagnasi pertumbuhan produktivitas, dan (2) Penurunan kapasitas lahan akibat adanya alih fungsi lahan tanaman pangan ke komoditi pertanian lainnya dan non pertanian.

Sistem tanam jajar legowo merupakan sistem tanam yang memperhatikan larikan tanaman, sistem tanam jajar legowo merupakan tanam berselang seling antara 2 atau lebih baris tanaman padi dan satu baris kosong. Keuntungan dari sistem tanam jajar legowo adalah menjadikan semua tanaman atau lebih banyak tanaman menjadi tanaman pinggir. Tanaman pinggir akan memperoleh sinar matahari yang lebih banyak dan sirkulasi udara yang lebih baik, unsur hara yang lebih merata, serta mempermudah pemeliharaan tanaman (Mujisihono et al., 2001). Penelitian ini bertujuan untuk mengetahui sistem tanam yang terbaik sehingga diperoleh pertumbuhan dan hasil yang optimal padi sawah.

\section{METODE}

Penelitian dilaksanakan di lahan sawah Petani Piruko Sitiung, Kabupaten Dharmasraya, Sumatera Barat. Kegiatan dilaksanakan bulan Mei sampai Desember 2009. Lokasi penelitian terletak pada ketinggian $140 \mathrm{~m}$ diatas permukaan laut, dengan jenis tanah podzolik merah kuning.

Penelitian disusun menggunakan Rancangan Acak Kelompok (RAK) dengan empat ulangan. Perlakuan yang diuji adalah 5 (lima) macam sistem tanam yaitu; (A) jajar legowo 2:1, (B) jajar legowo 4:1, (C) jajar legowo 6:1, (D) jajar legowo 8:1, dan (E) tanpa jajar legowo (kontrol). Bibit yang diuji adalah VUB Batang Piaman, ditanam sebanyak 3 batang per rumpun, jarak tanam $25 \times 25 \mathrm{~cm}$. Pupuk diberikan sebanyak $200 \mathrm{~kg}$ Urea, $100 \mathrm{~kg}$ SP36, dan $50 \mathrm{~kg} \mathrm{KCl}$ per hektar yang diberikan pada 1, 4, dan 7 minggu setelah tanam (mst), sedangkan pupuk SP36 diberikan seluruhnya pada umur 1 mst bersamaan pemberian Urea dan $\mathrm{KCl}$. Penyiangan dilakukan secara manual sebanyak 2 kali, yaitu pada umur 3 dan 6 minggu setelah tanam. Pada saat tanam diaplikasikan insektisida (Carbofuran) sebanyak $17 \mathrm{~kg}$ per hektar. Pengendalian penyakit blas dengan menggunakan fungisida fujiwan dengan takaran $2 \mathrm{ml}$ per liter air. Pengamatan dilakukan terhadap tinggi tanaman, jumlah anakan maksimum, jumlah anakan produktif, komponen hasil dan hasil. 


\section{HASIL DAN PEMBAHASAN}

\section{Pertumbuhan Tanaman}

Komponen pertumbuhan tanaman yang diamati adalah tinggi tanaman dan jumlah anakan (maksimum dan produktif). Hasil penelitian menunjukkan bahwa tanam jajar legowo tidak mempengaruhi secara nyata terhadap tinggi tanaman, tetapi berpengaruh nyata terhadap anakan maksimum dan anakan produktif, hal ini disajikan dalam tabel 1.

Tabel 1 Rataan anak maksimum, anak produktif, dan tinggi tanaman, padi sawah varietas Batang Piaman. Kecamatan Sitiung Kab. Dharmasraya. 2009.

\begin{tabular}{lccc}
\hline \multicolumn{1}{c}{ Sistem tanam } & $\begin{array}{c}\text { Anak maksimum } \\
\text { (btg/rumpun) }\end{array}$ & $\begin{array}{c}\text { Anak produktif } \\
\text { (btg/rumpun) }\end{array}$ & Tinggi tanaman $(\mathrm{cm})$ \\
\hline Jajar legowo 2:1 & $18,65 \mathrm{~b}$ & $15,70 \mathrm{~b}$ & $102,7 \mathrm{a}$ \\
Jajar legowo $4: 1$ & $18,70 \mathrm{~b}$ & $15,80 \mathrm{~b}$ & $103,0 \mathrm{a}$ \\
Jajar legowo 6:1 & $20,90 \mathrm{a}$ & $17,80 \mathrm{a}$ & $102,0 \mathrm{a}$ \\
Jajar legowo 8:1 & $20,85 \mathrm{a}$ & $17,75 \mathrm{a}$ & $103,3 \mathrm{a}$ \\
Tanpa Jajar Legowo & $20,60 \mathrm{a}$ & $17,70 \mathrm{a}$ & $102,2 \mathrm{a}$ \\
KK (\%) & 9,60 & 7,16 & 5,76 \\
\hline
\end{tabular}

Angka pada lajur yang diikuti huruf yang sama berbeda tidak nyata menurut uji DMRT 5\%.

Pada Tabel 1 terlihat bahwa jumlah anak maksimum dan produktif lebih banyak pada perlakuan jajar legowo 6:1, jajar legowo 8:1 dan tanpa jajar legowo dibanding jajar legowo 2:1 dan jajar legowo 4:1. Ini berarti bahwa varietas Batang Piaman cendrung memberikan jumlah anakan maksimum dan anakan produktif lebih banyak bila ditanam pada populasi yang lebih sedikit. Berbeda dengan hasil penelitian Abdullah (2000) pada varietas Batang Anai, dan Ridwan (2000) pada varietas Cisokan dan IR 42. Hal ini membuktikan bahwa respon tanaman terutama jumlah anak maksimum dan anakan produktif terhadap sistem tanam padi sawah dipengaruhi oleh sifat genetik tanaman. Sistem tanam jajar legowo memberikan ruang yang berbeda dalam memperoleh cahaya matahari yang dipergunakan dalam proses fotosintesis. Semakin banyak cahaya matahari yang bisa diserap tanaman semakin cepat proses fotosintesis berlangsung dan pada akhirnya mempercepat pertumbuhan tanaman. Jarak tanam yang lebar pada sistem jajar legowo mengakibatkan tanaman dapat tumbuh lebih leluasa sehingga ketersediaan unsur hara dapat diserap lebih optimal oleh tanaman.

\section{Komponen Hasil}

Komponen hasil tanaman yang diamati adalah panjang malai, jumlah gabah per malai, persentase gabah hampa, dan berat 1000 butir. Hasil penelitian menunjukkan bahwa perlakuan sistem tanam mempengaruhi secara nyata terhadap panjang malai, dan jumlah gabah per malai. Sedangkan persentase gabah hampa dan berat 1000 butir tidak menunjukkan pengaruh secara nyata (Tabel 2).

Tabel 2 Rataan panjang malai, jumlah gabah per malai, persentase gabah hampa per malai, dan bobot 1000 butir, padi sawah varietas Batang Piaman. Kec. Sitiung, Kab. Dharmasraya.

\begin{tabular}{lccccc}
\hline \multicolumn{1}{c}{ Sistem tanam } & $\begin{array}{c}\text { Panjang malai } \\
(\mathrm{cm})\end{array}$ & $\begin{array}{c}\text { Jumlah gabah } \\
\text { per malai (btr) }\end{array}$ & $\begin{array}{c}\text { Persentase hampa } \\
(\%)\end{array}$ & $\begin{array}{c}\text { Berat 1000 butir } \\
(\mathrm{g})\end{array}$ \\
\hline Jajar legowo 2:1 & $30,8 \mathrm{a}$ & $131,0 \mathrm{~b}$ & $21,30 \mathrm{a}$ & $26,13 \mathrm{a}$ \\
Jajar legowo 4:1 & $24,3 \mathrm{~b}$ & $143,3 \mathrm{a}$ & $20,50 \mathrm{a}$ & $24,68 \mathrm{a}$ \\
Jajar legowo 6:1 & $22,7 \mathrm{bc}$ & $120,0 \mathrm{c}$ & $19,85 \mathrm{a}$ & $27,21 \mathrm{a}$ \\
Jajar legowo 8:1 & $23,2 \mathrm{bc}$ & $121,0 \mathrm{c}$ & $22,00 \mathrm{a}$ & $26,10 \mathrm{a}$ \\
Tanpa Jajar Legowo & $21,8 \mathrm{c}$ & $120,3 \mathrm{c}$ & $21,80 \mathrm{a}$ & $24,68 \mathrm{a}$ \\
KK (\%) & 5,14 & 4,50 & 4,63 & 6,20 \\
\hline
\end{tabular}

Angka pada lajur yang diikuti huruf yang sama berbeda tidak nyata menurut uji DNMRT 5\%. 
Pada Tabel 2 terlihat bahwa panjang malai berkisar 21,8-30,8 cm, dimana malai terpanjang didapat pada jajar legowo 2:1 $(30,8 \mathrm{~cm})$ dan berbeda nyata dengan perlakuan lainnya. Jumlah gabah per malai berkisar 120,0-143,3 butir, dimana yang terbanyak didapat pada perlakuan jajar legowo 4:1 (143,3 butir) dan berbeda nyata dengan perlakuan lainnya. Jumlah gabah yang terendah ditunjukkan pada perlakuan jajar legowo 6:1 (120,0 butir), tidak berbeda nyata dengan tanpa jajar legowo (120,3 butir), dan jajar legowo 8:1 (121,0 butir), berbeda nyata dengan perlakuan jajar legowo 2:1 (131,0 butir) dan jajar legowo 4:1 (143,3 butir). Ada kecendrungan bahwa semakin banyak populasi tanaman maka jumlah gabah juga semakin meningkat. Hal ini disebabkan makin banyak lorong yang terdapat pada sistem tanam jajar legowo mengakibatkan intensitas cahaya matahari yang sampai ke permukaan daun lebih banyak terutama pada pinggir lorong sehingga meningkatkan efisiensi fotosintesa (Abdullah et al., 2000). Selanjutnya Fagi dan De Datta (1981) serta Darwis (1982), menyatakan bahwa laju serapan hara oleh akar tanaman cenderung meningkat dengan meningkatnya intensitas cahaya matahari.

\section{Hasil Gabah}

Pada Tabel 3 terlihat, persentase peningkatan hasil gabah kering panen berkisar 19,90$22,00 \%$ dibandingkan dengan tanpa jajar legowo. Rata-rata hasil gabah yang diperoleh pada perlakuan jajar legowo 2:1 (6,40 ton per hektar), jajar legowo 4:1 (6,45), jajar legowo 6:1 (6,24 ton per hektar), dan jajar legowo 8:1 (6,30 ton per hektar) berbeda nyata dengan perlakuan tanpa jajar legowo (4,25 ton per hektar). Menurut Hamzah dan Atman (2000), peningkatan hasil gabah ini antara lain disebabkan oleh meningkatnya populasi tanaman padi. Selain pengaruh populasi tanaman, peningkatan hasil gabah juga disebabkan oleh meningkatnya nilai komponen hasil

Tabel 3. Rataan peningkatan hasil dan hasil, padi sawah varietas Batang Piaman. Kecamatan Sitiung, Kab. Dharmasraya. 2009.

\begin{tabular}{lcc}
\hline \multicolumn{1}{c}{ Sistem tanam } & Peningkatan hasil $(\%)$ & Hasil gabah (t/ha) \\
\hline Jajar legowo 2:1 & 21,50 & $6,40 \mathrm{a}$ \\
Jajar legowo 4:1 & 22,00 & $6,45 \mathrm{a}$ \\
Jajar legowo 6:1 & 19,90 & $6,24 \mathrm{a}$ \\
Jajar legowo 8:1 & 20,50 & $6,30 \mathrm{a}$ \\
Tanpa Jajar Legowo & - & $4,25 \mathrm{~b}$ \\
KK (\%) & & 7,64 \\
\hline Ang
\end{tabular}

Angka pada lajur yang diikuti huruf yang sama berbeda tidak nyata menurut uji DNMRT 5\%.

\section{KESIMPULAN DAN SARAN}

Sistem tanam jajar legowo berpengaruh nyata terhadap komponen agronomis tanaman, terutama pada jumlah anak maksimum dan jumlah anakan produktif. Sedangkan pada tinggi tanaman pengaruhnya tidak nyata. Sistem tanam jajar legowo berpengaruh nyata terhadap komponen hasil dan hasil, terutama pada panjang malai, jumlah gabah per malai, dan hasil gabah kering panen, dan tidak berpengaruh nyata pada persentase gabah hampa serta bobot 1000 butir. Sistem tanam jajar legowo dapat meningkatkan hasil gabah kering panen sekitar 19,90-22\%. Untuk mendapatkan hasil yang optimal disarankan menggunakan sistem tanam secara jajar legowo. 
Jurnal Penelitian Pertanian Terapan

\section{DAFTAR PUSTAKA}

Abdullah, S. 2000. Teknologi P-starter Dengan Sistem Tanam Legowo (Shaf) Pada Budidaya Padi Sawah. Prosiding Seminar Nasional Hasil-hasil Penelitian dan Pengkajian Pertanian. Buku I. Sukarami, 21-22 Maret 2000. Puslitbang Sosial Ekonomi Pertanian Bogor; 76-81 hlm.

Abdullah, S., I. Syamsiah, dan A. Taher. 2000. Teknologi P-starter dengan sistem tanam bershaf (Teknologi SHAFTER). Makalah disampaikan pada kegiatan Sosialisasi Teknologi Pertanian di BPP Buayan Kecamatan Batang Anai Sumatera Barat tanggal 28 Oktober 1999. BPTP Sukarami: $10 \mathrm{hlm}$.

Darwis, S. N. 1982. Efisiensi Pemupukan Nitrogen Terhadap Padi Sawah Pada Berbagai Lokasi Agroklimat. Desertasi Doktor, Fakultas Pasca Sarjana Institut Pertanian Bogor.

Fagi, A. M. dan S. K. De Datta. 1981. Environmental Factors Affecting Nitrogen Efficiency In Flooded Tropical Rice. Fertilizer Research 2:52-67 p.

Hafsah, M. J. 2003. Kebijakan Peningkatan Produksi Padi Melalui Kegiatan Peningkatan Produktivitas Padi Terpadu (P3T). Prosiding Lokakarya Pelaksanaan Program Peningkatan Produktivitas Padi Terpadu (P3T) Tahun 2002. Puslitbangtan Bogor; 1-24 hlm.

Hamzah, Z. dan Atman. 2000. Pemberian Pupuk SP36 dan System Tanam Padi Sawah Varietas Cisokan. Prosiding Seminar Nasional Hasil-Hasil Penelitian dan Pengkajian Pertanian. Buku I. Puslitbang Sosial Ekonomi Pertanian Bogor; 89-92 hlm.

Las, I. H. Syahbuddin, E. Surmaini, dan Achmad M. Fagi. 2008. Iklim dan Tanaman Padi: Tantangan dan Peluang. Dalam: Suyamto et al (Eds) Buku Padi, Inovasi Teknologi dan Ketahanan Pangan, Balai Besar Penelitian Tanaman Padi, Badan Litbang Pertanian. 151$189 \mathrm{hlm}$.

Mujisihono, R. dan T. Santosa. 2001. Sistem Budidaya Teknologi Tanam Benih Langsung (TABELA) dan Tanam Jajar Legowo (TAJARWO). Makalah Seminar Perekayasaan Sistem Produksi Komoditas Padi dan Palawija. Diperta Provinsi D.I. Yogyakarta.

Nur, M., Marwan, H. M., dan Basri, A. B. 2003. Pengelolaan Tanaman Terpadu Naggroe Aceh Darussalam. Prosiding Lokakarya Pelaksanaan Program Peningkatan Produktivitas Padi Terpadu (P3T) Tahun 2002. Puslitbangtan Bogor; 49-68 hlm.

Purwanto. S. 2008. Implementasi Kebijakan Untuk Pencapaian P2BN. Dalam. B. Suprihatno et al. (Eds). Hasil-hasil Penelitian Padi Menunjang P2BN. Prosid. Seminar Apresiasi (Buku I), Balai Besar Penelitian Tanaman Padi, Badan Litbang Pertanian. 9-37 hlm.

Ridwan. 2000. Pengaruh Populasi Tanaman Dan Pemupukan P Pada Padi Sawah Dengan Sistem Tanam Jajar Legowo. Prosiding Seminar Nasional Hasil-hasil Penelitian dan Pengkajian Pertanian. Buku I. Sukarami, 21-22 Maret 2000. Puslitbang Sosial Ekonomi Pertanian Bogor; 65-69 hlm. 